\title{
A ideia de povo brasileiro nas lições de História do professor Joaquim Silva
}

Idea of Brazilian People in the Teacher

Joaquim Silva's History Lessons

Arnaldo Pinto Junior*

Halferd Carlos Ribeiro Junior ${ }^{\star *}$

\section{RESUMO}

Este artigo focaliza a ideia de povo brasileiro impressa na obra didática de Joaquim Silva, um dos autores escolares mais conhecidos em meados do século XX. Ao considerarmos o cenário da Era Vargas e as transformações decorrentes da Reforma Capanema, localizamos nos textos do autor evidências de disputas em torno das narrativas sobre a formação do país e de seu povo. O corpus documental da pesquisa, composto por programas de ensino, livros didáticos e leis concernentes à educação, foi analisado a partir de referenciais teórico-metodológicos que potencializaram reflexões acerca dos processos de construção social do currículo e de produção das obras escolares. Por fim, concluímos que a História ensinada por Silva procurava tanto valorizar a origem mestiça da população quanto reforçar o lugar central do elemento português e de sua cultura em nossa sociedade.

Palavras-chaves: História do ensino de História; currículo; livro didático.

\section{ABSTRACT}

This article focuses on the idea of Brazilian people printed on the Joaquim Silva's didactic work, one of the best known school authors in the middle of the twentieth century. As we consider the Vargas Era scenario furthermore the transformations arising from the Capanema Reform, we situated among the author's texts some evidence related to disputes over the narratives about the country and its people formation. The research documental corpus, composed by teaching programs, textbooks and laws concerning education, was analyzed starting from theoretical-methodological references which potentiate reflections about the curriculum's social construction procedures and the schoolwork production. Lastly, we conclude that History taught by Silva it sought as much to appreciate the population mestizo origin as to reinforce the Portuguese element and its culture's central place in our society.

Keywords: History of History teaching; curriculum; textbook.

\footnotetext{
* Universidade Estadual de Campinas (UNICAMP), Campinas, SP, Brasil. apjbrasil@hotmail.com

** Universidade Federal da Fronteira Sul - Campus Erechim, Erechim, RS, Brasil. halferd.junior@ uffs.edu.br
} 
O brasileiro não conhece o orgulho de ser. Nasceu ouvindo desdenhar dos antepassados [...] Sahindo do terreno da vida para o da sciencia, acceitou sem verificação axiomas firmadas em doutrinas ainda conjecturaes [...] Convenceu-se, sincera e fundamente, de que é inferior o typo brasileiro. E desse principio tirou a dedução de que "o Brasil é um paiz perdido". (Pereira, 1930, p. 5)

Thomas Skidmore (1969), interessado em compreender a estrutura burocrática do Estado brasileiro à época do Golpe Civil-Militar de 1964, verificou que sua modernização teve início a partir de outro golpe, mais conhecido como Revolução de 1930. Para o autor, Getúlio Vargas e seus correligionários políticos promoveram um conjunto de ações visando a centralização administrativa, como também buscaram acelerar o processo de industrialização e urbanização, bases fundamentais da então propalada "sociedade moderna".

Com o intuito de pôr em prática tais projetos, Getúlio Vargas teve amplo apoio de diversos setores da sociedade brasileira, como dos oligarcas dissidentes da Primeira República, setores das forças militares, das elites intelectuais e da Igreja Católica. Nesse empreendimento de construção de um Estado às avessas da política liberal, era necessário um projeto de nação que envolvesse o povo na tarefa de alcançar o progresso na perspectiva dos padrões da civilização ocidental.

Segundo Boris Fausto (2006), os princípios positivistas em voga no Rio Grande do Sul defendiam a transformação do Brasil, mesmo que fosse necessária uma intervenção autoritária no Estado a fim de promover a modernização e a formação do povo, que viabilizasse a construção e o progresso desse país idealizado.

Além das reformas administrativas, o governo de Vargas empreendeu ações que objetivavam a construção de uma identidade que estivesse atinente aos princípios do projeto em tela. No estudo referente à política cultural e suas implicações para a constituição de uma cultura histórica entre 1937 e 1945, Ângela de Castro Gomes (2007, p. 49) argumenta que 
a construção de uma cultura política e de uma cultura histórica, por conseguinte, vincula-se fortemente à implementação de políticas públicas, em particular sob regimes autoritários, que investem de maneira consciente e eficiente na busca de sua legitimidade, mobilizando valores, crenças e tradições da sociedade, com destaque para os que se referem a uma herança e passado comuns. [...] em que a leitura do passado ganha espaço privilegiado; onde o que se está chamando de cultura histórica é dimensão constitutiva e também estratégica da cultura política. (GOMES, 2007, p. 49)

Tendo como fonte documental os artigos publicados na revista mensal Cultura Política dirigida por Almir de Andrade, publicada entre 1941 e 1945 pelo Departamento de Imprensa e Propaganda (DIP), Gomes constatou algumas características centrais nos textos produzidos com o objetivo de descrever a identidade desejada: a necessidade da construção de uma consciência que serviria de lastro para a manutenção dos vínculos entre os brasileiros, fundamentando a unidade e a homogeneidade cultural da nação; a revalorização do passado, rediscutindo a formação do povo brasileiro, a colonização e o seu tipo ideal; e, por fim, a percepção do fundamento cristão e humanístico da identidade nacional.

Pensando em tais características identitárias, agentes do Estado empreenderam uma releitura do passado, valorizando-o positivamente e trabalhando para sua divulgação a um amplo espectro da sociedade, por meio de eventos e ações que pudessem dialogar com uma determinada visão de História, deixando evidente a interpretação pretendida. O estabelecimento de um calendário de comemorações cívicas e a elaboração de estratégias de divulgação, que incluíram atividades escolares, a realização de congressos, as manifestações de massa e o explícito apoio da imprensa, contribuíram com o processo de legitimação desses valores, tanto perante às gerações em formação como à sociedade em geral.

No período em que Vargas esteve à frente do governo federal ocorreu uma trama complexa de ações envolvendo a transformação do Estado e a construção de uma cultura política voltada para a defesa da identidade nacional. Em relação às ações de fortalecimento do Estado, podemos destacar as esferas econômica, política e social, enquanto para a construção da identidade nacional, o foco central esteve na política cultural e na educação.

No estudo referente ao Estado Novo, os pesquisadores Simon Schwartzman, Helena Bomeny e Vanda Costa (2000) afirmam que o projeto de recons- 
trução da nação vigente nessa fase histórica teve dois aspectos fundamentais: o ideológico e o repressor. Do ponto de vista ideológico, foram construídos simbolicamente os fundamentos da nação e, do repressor, foi adotada uma política agressiva de exclusão e inserção das comunidades estrangeiras no Brasil que mantinham quase que inalterada a cultura de sua terra de origem. " $\mathrm{Pa}$ recia impossível construir uma nacionalidade com a simultânea convivência de diferenças culturais. Construir o nacionalismo era, ao mesmo tempo, destruir as diferenças e proceder a uma seleção na formação da cidadania brasileira" (SCHWARTZMAN, BOMENY e COSTA, 2000, p. 165). Assim sendo, o Estado proibiu a importação de livros didáticos, escolas foram fechadas e o ensino no Brasil somente poderia ser ministrado em português. No sentido ideológico, o sistema de ensino cumpriu um papel fundamental de divulgação dos princípios valorizados pelo Estado.

Ao definir o inimigo da nação, não necessariamente construía-se a representação do brasileiro. Assim, era importante responder a indagação: quem era o brasileiro? Como desdobramento dessa questão, mas com uma tensão entre o presente e o passado nos anos 1930, havia a preocupação de qualificar quem era o povo brasileiro, como foi a sua formação e definir o seu caráter fundamental.

Em seu estudo acerca das práticas políticas na Era Vargas, Alcir Lenharo afirmou que a figura heroica do bandeirante foi compreendida como o modelo ideal de brasileiro, que impulsionava o espírito nacional e auxiliava a construção do Estado. O bandeirante representava, simbolicamente, a ideia de expansão e consolidação do território, de ímpeto transformador e da conquista de riqueza, promovendo o progresso e o surgimento de uma estrutura administrativa pautada na mistura étnica e na hierarquização.

Nesta democratização pela mestiçagem, três traços psicológicos formam a trama moral de cada bandeira: comando, obediência e movimento. $\mathrm{O}$ índio contribui com o seu alto grau de adaptação e mobilidade no meio natural; o negro com a abundância de sentimento, calor humano e experiência sedentária nas lavras e na agricultura; o português com o seu espírito de aventura, capacidade de organização e comando. (LENHARO, 1986, p. 62)

Nesse aspecto, as elites políticas e intelectuais que atuaram durante o Estado Novo optaram por uma interpretação sobre a formação do povo brasilei- 
ro que valorizava positivamente a figura do português. Em tal perspectiva, a relação entre os elementos étnicos branco, indígena e negro constituiu uma cultura com características próprias, a qual teve como alicerce a miscigenação. Mesmo contando com diferenças no seio de seu povo, distribuído no vasto território nacional, os brasileiros viviam organicamente sob a tutela do Estado.

Diante dessa dinâmica de revisão da cultura política e histórica implementada no bojo do Estado Novo, e um cenário internacional de crise dos princípios do capitalismo liberal, a ascensão dos regimes totalitários, e os conflitos da Segunda Guerra Mundial, a educação escolar foi o alvo de reformas educacionais a fim de garantir a transmissão dos princípios ideológicos valorizados pelo Estado Novo; o ensino de História foi o locus privilegiado desse projeto. Assim sendo, passamos à análise da reforma educacional, do currículo de História, e da interpretação de Joaquim Silva sobre o povo brasileiro.

\section{A REFORMA GUSTAVO CAPANEMA E O NOVO CURRÍCULO DE HISTÓRIA}

Ao abordarmos questões educacionais e as especificidades do currículo destinado ao ensino de História a partir da Reforma Capanema, buscamos as contribuições de Ivor Goodson (1995) para o desenvolvimento de nossas análises. Segundo o autor, é necessário entender a trajetória de formação de um determinado currículo, pois dessa forma torna-se possível a identificação dos grupos que disputavam o poder durante sua organização, além da compreensão de como tais grupos desejavam formar seus cidadãos na perspectiva da sociedade projetada para o futuro.

A luta para definir um currículo envolve prioridades sociopolíticas e discurso de ordem intelectual. A história dos conflitos curriculares do passado precisa, pois, ser retomada. Do contrário, nossos estudos sobre escolarização deixarão sem questionamento e análise uma série de prioridades e hipóteses que foram herdadas e deveriam estar no centro do nosso esforço para entender a escolarização na teoria e operacionalizá-la na prática. (GOODSON, 1995, p. 28)

Portanto, consideramos importante rever a trajetória histórica da construção do currículo definido pela Reforma Capanema. As disputas políticas 
em torno da decisão para prescrever uma determinada organização curricular representam as atuações de grupos sociais em busca da valorização de suas memórias, de suas versões sobre o passado, ações que contribuem para a formação dos sujeitos, de suas identidades individuais e coletivas, como também dos modelos éticos e morais de relação social.

A construção de um currículo requer escolhas, que em diversos casos do ensino da disciplina escolar História estabeleceu a seleção de eventos e sujeitos do passado a fim de legitimar uma narrativa hegemônica acerca do surgimento e consolidação do Estado nacional. Nesse processo estão presentes valores de determinados grupos sociais, as memórias a serem cristalizadas e preservadas pela sociedade, reforçando tradições e poderes.

Antes da década de 1930 no Brasil, a responsabilidade de organizar os programas curriculares recaía sobre a Congregação do Colégio Pedro II (GASPARELLO, 2004). Os programas eram elaborados pelos seus professores catedráticos e submetidos à aprovação do colegiado reunido na referida instância. Uma escola para ser equiparada ao Colégio Pedro II deveria adotar toda a sua estrutura pedagógica. Assim sendo, o Colégio Pedro II ditava os fundamentos da organização das escolas brasileiras desde a sua fundação em 2 de dezembro de 1837.

Em 1931, com a Reforma Francisco Campos, de reorganização do sistema de ensino secundário brasileiro, o Estado, por meio do Ministério dos Negócios da Educação e Saúde Pública, ${ }^{1}$ tomou para si a responsabilidade de elaboração dos programas curriculares, retirando do Colégio Pedro II a prerrogativa que gozava desde a sua fundação. Para tanto, o Ministério dos Negócios da Educação e Saúde Pública deveria compor comissões a fim de elaborar a estrutura e organização curricular (DALLABRIDA, 2009).

Para o ensino de História, a Reforma Francisco Campos adotou a concepção de História da Civilização, que incluía conteúdos de História Geral, da América e do Brasil, de forma que a história brasileira era estudada no decorrer dos assuntos da disciplina História da Civilização. A organização curricular era pautada na ideia de pontos, ou seja, uma lista de temas que seriam trabalhados pelo professor durante o ano letivo.

Segundo Luís Reznik (1992, p. 108), “após a implantação do Estado Novo, criou-se um clima intelectual e político propício para redirecionar o sentido do ensino de História no secundário”. Diante desse cenário, o fervor patriótico 
foi fortalecido, de forma que a ideia de reconstruir a nação foi assumida por diversos setores sociais. No entanto, setores da sociedade compreendiam que a responsabilidade da implementação desse projeto cabia ao Estado, o que acarretou uma mobilização pública a fim de influenciar a tomada de decisão do governo.

De acordo com Reznik, em 1938 foi organizada uma "Maratona Intelectual" para a disciplina História da Civilização, em que foi solicitado ao Instituto Histórico e Geográfico Brasileiro (IHGB) que oferecesse ao aluno vencedor um prêmio, além do que seria concedido pelo então denominado Ministério da Educação e Saúde. O IHGB propôs oferecer ao aluno o livro História do Brasil, de Handelman, que fora traduzido e publicado pela própria instituição. Todavia, o ministério indicou que esse prêmio deveria ser apenas para o aluno da quinta série, tornando evidente que a História do Brasil possuía um tempo reduzido no currículo, estabelecendo um paradoxo entre o desejo patriótico e seu estudo no ensino secundário. Posicionando o seu desacordo em relação ao currículo vigente, o IHGB pronunciou que era favorável ao ensino da História pátria de maneira autônoma em várias séries da educação escolar.

Frente a essa questão, ocorreram vários debates na sociedade solicitando a autonomia do ensino da História do Brasil em relação à História da Civilização. Em 1938, no III Congresso Nacional de História do IHGB, foi aprovada a moção solicitando a autonomia para a disciplina História do Brasil, ao mesmo tempo em que elogiava as iniciativas das escolas de ensino superior que acrescentaram essa disciplina em seu currículo (REZNIK, 1992). Em 1939, o Colégio Militar, por iniciativa própria, incluiu na sua grade curricular a disciplina História do Brasil. Essa campanha não ficou restrita aos debates acadêmicos e pedagógicos nas instituições de ensino, também contou com a participação da imprensa.

O jornal Correio da Manhã, aproveitando o ensejo do recém restabelecimento de História do Brasil no Colégio Militar, inicia uma campanha com reportagens, entrevistas, editoriais e artigos quase diários a favor da criação daquela disciplina. A amplitude da campanha - por si só abrangente já que verificada pela diversidade de depoimentos coletados: o inspetor de educação do Colégio Militar, catedráticos do Colégio Pedro II, o reitor da Universidade do Brasil, o presidente do IHGB, o diretor do Arquivo Nacional, além de articulistas com peso político 
social como o Padre Arlindo Vieira, o editorialista Costa Rego ou o literato Bastos Tigre. (REZNIK, 1992, p. 110)

De acordo com Reznik, essa campanha em prol da autonomia da História do Brasil no currículo do ensino secundário teve como lógica discursiva que o estudo da História pátria pela juventude era o caminho mais adequado para combater as ideias consideradas perniciosas, como o comunismo. Em decorrência dessa questão, o enfoque na História da Civilização foi considerado pernicioso, pois poderia fundamentar na juventude as encruzilhadas ideológicas presentes na Europa, reafirmando a necessidade da autonomia da História do Brasil.

Em 1940, o ministro Gustavo Capanema pronunciou no Colégio Pedro II o restabelecimento da disciplina História do Brasil no ensino secundário. Ficou evidente o clamor de setores da sociedade para a manutenção da autonomia e da importância da História do Brasil na formação da juventude brasileira. Dinâmica que esteve presente na organização curricular do ensino de História a partir da Reforma Gustavo Capanema. Com a reorganização do ensino secundário em abril de 1942, tornou-se novamente mister a reformulação do currículo.

Em decorrência dos debates relativos à autonomia da História do Brasil, a Lei Orgânica do Ensino Secundário (1942) determinou o ensino da História Geral e da História do Brasil, com especial relevo para a História do Brasil, descartando as denominações História Universal e História da Civilização. Para o desenvolvimento do sentimento patriótico nas escolas, foi colocado em simultaneidade o estudo dos aspectos históricos e geográficos do Brasil nos últimos anos do ginásio.

Visando a seleção dos temas que deveriam compor o currículo do ensino de História, foram consultados Delgado de Carvalho e Jonathas Serrano, professores que possuíam relações diretas com o Ministério da Educação. Segundo Reznik, para o primeiro tema da História do Brasil na terceira série ginasial, o Descobrimento, Delgado de Carvalho destacou que deveria ser estudado o Ciclo Ocidental de Navegação, enquanto Jonathas Serrano mencionava estritamente as viagens diretamente ligadas ao Descobrimento do Brasil. Em relação ao Elemento Indígena, Carvalho propôs o estudo dos diversos grupos indígenas brasileiros, a sua distribuição geográfica, além da organização política e cultu- 
ral; Serrano defendia o estudo da catequese, da figura de José de Anchieta e a influência do elemento indígena. Desse modo, é evidente a diferença de concepção de currículo e de interpretação histórica entre os especialistas consultados. Delgado de Carvalho deseja uma estruturação curricular mais detalhada, com todos os temas que deveriam ser tratados em sala de aula; Serrano preferia oferecer menos opções para o professor, mas aglutinando o conceito que considerava mais interessante, como no caso do estudo do elemento indígena, que priorizava não a cultura indígena em si, mas a ação da Igreja Católica em catequizar esse grupo, para, a partir desse princípio, perceber a influência indígena na formação do povo brasileiro, deixando explícita uma interpretação histórica que considerava fundamental a participação do clero na configuração cultural da nação.

Reznik compreendeu que essas duas propostas representam os embates e polêmicas sobre a historiografia didática desde o início da década de 1930, nos quais alinhavam-se, de um lado, os defensores de uma História tradicional dos eventos e, de outro lado, os sujeitos que se autodenominavam renovadores do ensino da disciplina. Dentre esses sujeitos encontrava-se Serrano, que propugnava uma interpretação histórica voltada para a formação da consciência patriótica (REZNIK, 1992, p. 125). A interpretação de Serrano foi preponderante na elaboração da proposta curricular do ensino de História para o ginásio.

Como já afirmamos, com a publicação da Lei Orgânica do Ensino Secundário em abril de 1942, tornou-se necessária a reformulação do currículo. O ministro da Educação, Gustavo Capanema, em 27 de abril de 1942, por meio da Portaria Ministerial no 101, nomeou a comissão responsável pela elaboração do programa curricular destinado ao ramo ginasial do ensino secundário. A referida comissão era composta pelos seguintes integrantes: o próprio ministro, na condição de presidente, o diretor do Instituto Nacional de Estudos Pedagógicos como secretário e, sem cargos específicos, o diretor-geral do Departamento Nacional de Educação, o diretor da Divisão de Ensino Secundário e o diretor da Divisão de Educação Física, ou seja, representantes do alto escalão da estrutura administrativa do sistema de ensino federal, somados aos renomados professores ${ }^{2}$ responsáveis pela elaboração do currículo.

A composição da comissão para organização curricular com o alto escalão do Ministério da Educação e por importantes figuras da educação brasileira no período denotava que seus integrantes estavam de acordo com os princípios 
políticos do Estado, como os professores do Colégio Pedro II Jonathas Serrano e Euclides Roxo. O primeiro foi examinador dos livros didáticos da disciplina História na Comissão Nacional do Livro Didático (CNLD), criada em 1938 (FERREIRA, 2008); o segundo foi o responsável pela construção da matriz curricular de Matemática da Reforma Francisco Campos de 1931.

Por meio do conjunto de verbos (prescrever, dever, seguir) utilizados pela comissão para definir as funções tanto do professor quanto dos alunos, o ministro da Educação deixou evidente que todos envolvidos no processo pedagógico deveriam atuar de acordo com os princípios do governo. O programa curricular não teve um caráter de orientação da ação pedagógica docente, mas de prescrição dos temas que deveriam ser abordados em sala de aula e da maneira como eles deveriam ser ensinados.

A portaria normatizava os pressupostos do currículo, tendo três quesitos fundamentais como referência: por que ensinar (a justificativa)? O que ensinar (o conteúdo)? Como ensinar (a metodologia)? No entanto, a resposta para cada uma dessas questões teve como fundamento o pronunciado por Capanema em 2 de dezembro de 1937, no Colégio Pedro II: a educação deveria estar a serviço da nação, preparando o cidadão para viver em sociedade, de acordo com as diretrizes morais, políticas e econômicas que sustentavam a base ideológica do Estado Novo.

Diferentemente da Reforma Francisco Campos, que organizou o currículo em tópicos, ou seja, cada título era uma aula que deveria ser ministrada, a organização do ensino de História a partir da Reforma Capanema preconizava que o currículo deveria ser agrupado em unidades didáticas, ou seja, um tema geral que era formado por várias aulas. Assim, objetivava-se articular os conteúdos em sala de aula a uma temática mais abrangente e, se possível, abordada por várias disciplinas.

Os programas deveriam estar de acordo com as finalidades do ensino secundário definidas pelo artigo $1^{\circ}$ do Decreto-Lei no 4.244, de 9 de abril de 1942: favorecer a formação integral da personalidade dos adolescentes; acentuar a formação espiritual, a consciência patriótica e humanista; e preparar intelectualmente os alunos para darem continuidade aos estudos.

O artigo 9 da Reforma Capanema estabeleceu que o ensino secundário fosse articulado com o ensino primário, propiciando condições para os alunos continuarem os estudos no ensino superior. $\mathrm{O}$ artigo 42 estabeleceu que a 
relação entre professor e aluno fosse ativa, preparando-o intelectualmente com mais ênfase no aspecto qualitativo do ensino do que na grande quantidade de temas a serem abordados, com o intuito de contribuir para o amadurecimento de seu espírito. Nesse sentido, a escolarização formaria padrões de comportamento e de conduta social.

A Portaria Ministerial no 101 consolidou a opção pedagógica da Reforma Capanema, explicitando que os programas deveriam ser elaborados de acordo com o artigo 27. Assim, os estabelecimentos de ensino adotariam o processo pedagógico ativo, o qual daria sentido à vida dos alunos, cabendo ao responsável pela organização do programa curricular destacar essa proposta pedagógica por meio das instruções metodológicas que acompanhariam o programa curricular. Por fim, a portaria determinava que a organização curricular, o sumário e as orientações metodológicas seriam publicados no Diário Oficial, sob a responsabilidade do Ministério da Educação.

Coube a Jonathas Serrano a responsabilidade de elaborar o programa do ensino de História para o curso secundário. Serrano foi professor dessa disciplina no Colégio Pedro II, sócio do IHGB, membro da CNLD, autor de livros didáticos e de manuais de metodologias para o ensino da disciplina. Em seu estudo sobre o tema, Itamar Freitas (2006, p. 145) ressalta a ligação de Serrano com o titular da pasta da Educação:

É necessário registrar, contudo, a condição de católico militante e de homem próximo a Lourenço Filho e Gustavo Capanema. Isso, certamente, contou bastante para sua inclusão no seleto grupo que ditaria o padrão do novo didático brasileiro. (FREITAS, 2006, p. 145)

Segundo Beatriz Boclin M. dos Santos (2009), Serrano foi a figura de maior destaque no ensino de História entre o final dos anos 1920 e meados dos anos 1940, pois ocupou importantes cargos administrativos na área da educação e procurou inovar a proposta metodológica para a disciplina propondo que ela fosse centrada na reflexão e na crítica do passado, em detrimento da memorização, além de postular a separação entre a História Geral e a História do Brasil. No entanto, em sua interpretação histórica, manteve um discurso tradicional, pautado nos conceitos de civilização e de progresso, os quais consideravam como ápice da trajetória humana a sociedade europeia, condicionando a interpretação da História do Brasil aos acontecimentos do Velho Mundo. 
Serrano organizou o currículo da disciplina com base no conceito de unidade didática, como prescrevia a Portaria Ministerial no 101. Por isso, cada série teve 9 unidades didáticas. O principal destaque dessa organização curricular é o empenho em ampliar a carga horária do estudo da História do Brasil em relação à História Geral. Com mais de 3 mil anos, a História Geral seria trabalhada na escola dentro de 18 unidades didáticas nos dois primeiros períodos letivos do ensino secundário, momento em que a criança ainda está marcada, principalmente, pelo pensamento concreto, sendo favorável a uma História com base em episódios e menos analítica. Já a História do Brasil, com um recorte temporal de aproximadamente 450 anos à época, também tinha 18 unidades didáticas para tratar dos temas principais dispostos em 2 anos de estudo, quando os adolescentes iniciam o desenvolvimento cognitivo abstrato, portanto, na fase mais apropriada para as discussões históricas, com base em análises da sociedade que abordavam aspectos políticos, econômicos, sociais e culturais. ${ }^{3}$

O principal foco da organização curricular decorrente da Reforma Capanema foi o estudo da História do Brasil, visto que no decorrer da escolarização de 4 anos do ginásio, 50\% do tempo eram dedicados aos seus conteúdos. Em segundo plano ficava História da Europa, enquanto o estudo do Oriente e da América eram oferecidos em função dos acontecimentos europeus. Nessa organização curricular, o passado brasileiro não estava atrelado ao dos povos da América, ele se relacionava com a denominada "civilização" do Velho Mundo. Vale destacar que a África e a Ásia não apareciam diretamente no programa, o que reforçava a visão eurocêntrica dessa matriz.

Tendo em vista os propósitos desse texto, delimitaremos a nossa análise dos conteúdos relativos à formação étnica do povo brasileiro. ${ }^{4}$ Em relação à História do Brasil, Serrano não optou por descrever o modo de vida dos habitantes desse território antes da chegada dos portugueses. Pelo contrário, a primeira etapa de nossa História ocorreu na Europa, com a formação do Estado português e a sua expansão marítima. O título da primeira unidade do programa era $O$ Descobrimento, o que dificultava o estudo do passado e a valorização dos povos originários que habitavam essas terras antes da presença europeia.

Na segunda unidade, Serrano selecionou o papel do português como colono, considerando-o elemento fundamental da construção do Brasil, em detrimento do papel do indígena e do negro. Propôs o estudo da organização 
política administrativa de Portugal para a colonização do Brasil com a introdução das capitanias hereditárias e posterior implantação do Governo Geral. Do ponto de vista religioso, destacou a ação de catequização da Igreja Católica e suas relações com o projeto político do reino português.

Na terceira unidade, intitulada A Formação Étnica, Serrano propôs a abordagem sobre a formação do povo brasileiro, trabalhando com a relação entre as três raças: o branco, indígena e o negro. Ao definir a constituição do povo brasileiro como um grupo miscigenado, tendo a matriz europeia (no caso, a portuguesa) como fundamental, Serrano ancorou sua interpretação na proposta de Von Martius para a escrita da História nacional e em Varnhagen pela tradição intelectual do IHGB.

Após o tratamento dado à formação étnica, tornou-se necessário elencar a ação do povo no território brasileiro e a configuração do seu caráter cultural. Desse modo, Serrano prescreveu que deveria ser ensinando a expansão e a defesa do seu espaço, para que os alunos compreendessem o processo de construção e a importância de sua manutenção. Indiretamente se justificava a violência contra o elemento indígena, primeiro habitante do Brasil, pois o colono precisava combatê-lo para efetivar a conquista territorial e garantir o seu desenvolvimento.

A unidade VII, intitulada Desenvolvimento Espiritual, apresentava o elemento fundamental na construção do caráter cultural do brasileiro: a atuação dos jesuítas no trabalho de conversão do indígena e moralização do colono, ensinando os fundamentos da fé católica. Após a ação evangelizadora, Serrano propôs na unidade VIII o estudo da construção do sentimento nacional (com base nas revoltas coloniais) e do processo de independência, culminando com a emancipação política e a construção do Estado brasileiro. Assim, inferimos que Serrano compreendia que a sociedade brasileira era caracterizada por um povo mestiço, católico, com um sentimento nacional marcado pela defesa de seu território em meio ao desenvolvimento de suas estruturas administrativas.

Desse modo, o aluno no final do terceiro ano ginasial teria acesso à memória histórica em que criava uma representação sobre a formação do povo brasileiro e da construção do seu território e Estado. Com essa organização curricular, Serrano elaborou uma representação de sociedade em que sua raiz estava na civilização europeia; o povo brasileiro era mestiço, com a principal ascendência portuguesa; o caráter cultural do povo era fundamentado na fé 
católica e no sentimento patriótico; o Estado deveria defender os interesses da nação, mesmo que para atingir tal objetivo fosse necessária a centralização administrativa e o cerceamento da liberdade do cidadão.

Com a apresentação dessa dinâmica de construção do currículo, compreendemos que o principal agente envolvido foi o Estado. Entretanto, na execução do projeto foram travadas disputas no âmbito do Ministério da Educação e Saúde, pois a proposta de Delgado de Carvalho que defendia a prescrição curricular com mais detalhes em cada unidade didática, as concepções de História Universal e História da Civilização, a ênfase do ensino de História Geral em relação à História do Brasil, foram deixadas de lado. A proposta adotada, com ênfase no ensino de História do Brasil, denotava o momento de clamor social pelo sentimento pátrio na dinâmica da Segunda Guerra Mundial, em concordância com as perspectivas ideológicas do Estado Novo. A prescrição curricular de Serrano foi elaborada de acordo com seus princípios pedagógicos e historiográficos, uma interpretação profundamente marcada pela presença da Igreja Católica para a construção do Brasil, a valorização da herança colonial portuguesa, a defesa do Estado autoritário de Getúlio Vargas. O pressuposto de que o ensino de História deveria instigar a reflexão e a crítica, questionando a pura memorização de nomes e datas, foi organizado em unidades didáticas composta apenas pelos temas essenciais, com o intuito de viabilizar a autonomia didática do professor e estabelecer a compreensão da História como o repositório de exemplos de conduta moral.

Mas como essa proposta foi efetivada em sala de aula? Na busca de elementos para responder essa indagação, abordar apenas a prescrição curricular não é suficiente. Por isso, focalizamos a narrativa impressa no livro didático, o principal recurso de apoio que o professor tinha em mãos, configurando-se também como uma síntese dos programas de ensino, um currículo editado (ESCOLANO BENITO, 2006), um roteiro com textos e atividades para implantação prática em sua aula da prescrição curricular, o que no período do Estado Novo poderia favorecer a consecução da identidade nacional. 
A FORMAÇÃO ÉTNICA DO POVO BRASILEIRO

NOS LIVROS DIDÁTICOS DE JOAQUIM SILVA

Constituída fundamentalmente pelas interpretações de intelectuais do primeiro quartel do século $\mathrm{XX}$, a memória histórica que pressupunha a incapacidade do Brasil em progredir, a exemplo das denominadas sociedades modernas, tornara-se uma visão incômoda para os sujeitos que acreditavam nos ideais civilizatórios. Entretanto, a partir da Revolução de 1930, os grupos que passaram a controlar as estruturas administrativas federais assumiram a responsabilidade de reconstruir o projeto de nação. Essa responsabilidade abarcava a configuração de uma nova interpretação da formação do povo brasileiro, da herança colonial portuguesa e do Estado (VESENTINI, 1997).

Para alcançar tal objetivo, as elites administrativas adotaram políticas voltadas a criação de uma nova representação do país e de seu povo, reconfigurando a memória histórica nacional por meio de produções intelectuais que estavam de acordo com seus princípios ideológicos. Dentre as estratégias implementadas, destacaram-se a promoção de diversas ações públicas para divulgar esses ideais, como desfiles cívicos e a nacionalização do sistema de ensino, o qual ficou incumbido de trabalhar com as bases morais, éticas e cristãs defendidas por seus agentes, utilizando as instituições escolares como meios privilegiados de divulgação da ideologia do Estado.

Pensando nos desdobramentos da reconfiguração da memória histórica nacional, analisamos livros didáticos do professor Joaquim Silva - os que mais circularam no ensino secundário da época -, focalizando a interpretação atribuída à formação étnica do povo brasileiro. Considerando que os sujeitos são constituídos no seu meio social e cultural, iniciamos nossa análise a partir da trajetória social e profissional de Joaquim Silva, as quais evidenciam elementos importantes para a compreensão dos nexos de sentido de sua narrativa histórica escolar.

Joaquim Silva ${ }^{5}$ nasceu em 23 de novembro de 1880 na cidade de Sorocaba (SP) e faleceu na capital do mesmo estado em 21 fevereiro de 1966, com 85 anos de idade (PINTO JUNIOR, 2010). A sua formação no magistério ocorreu na Escola Complementar de São Paulo, onde foi diplomado no dia 15 de dezembro de 1898.

Em março do ano seguinte, começou a lecionar no primeiro grupo esco- 
lar de sua cidade natal. Depois de 12 anos atuando como professor no magistério público, em março de 1911 mudou-se para Tatuí (SP), onde tomou posse do cargo de diretor do grupo escolar da cidade. Em 1914 retornou para Sorocaba, assumindo a direção do segundo grupo escolar da cidade, que recebeu o nome de Visconde de Porto Seguro, título nobiliárquico do historiador e diplomata Francisco Adolfo de Varnhagen. Silva permaneceu na direção dessa escola até 1921, quando foi nomeado professor da Escola Normal de Pirassununga (SP), na qual foi catedrático da cadeira de Psicologia e Pedagogia. Sua carreira no magistério público do estado de São Paulo foi encerrada em 1927, quando aposentou-se na condição de formador de professores.

Logo após deixar a carreira pública, mudou-se para a capital paulista onde integrou o corpo docente do recém-fundado Lyceu Nacional Rio Branco, ensinando História no curso ginasial. Também atuou em escolas confessionais ${ }^{6}$ de São Paulo e, concomitantemente, começou a escrever livros didáticos em um momento de transformações empreendidas no ensino secundário pelo governo Vargas.

Já em 1931 começou a trabalhar para a CEN [Companhia Editora Nacional], com a publicação de material didático destinado a preparação para o exame de admissão, obra coletiva. Como professor, sua atuação se intensificou na década de 1930. Além das aulas no Rio Branco, Joaquim Silva passou a trabalhar em instituições confessionais como o Colégio São Luís, o Colégio Madre Cabrini e o Ginásio das Cônegas de Santo Agostinho. (PINTO JUNIOR, 2010, p. 119)

A atuação docente de Joaquim Silva terminou em 1941. No entanto, suas atividades como autor de livro didático cessaram apenas com o falecimento, visto que seu nome era o mais importante da disciplina História da CEN até meados da década de 1960.

Do ponto de vista sociocultural, Joaquim Silva foi influenciado pela produção tipográfica de seu pai, um imigrante português que possuía um jornal em Sorocaba com o título O 15 de Novembro. Na passagem do século XIX para o XX, Joaquim Silva produzia matérias e o editorial do jornal, defendendo ideais republicanos. A maçonaria foi o espaço inicial de fundamentação de seu posicionamento político, colocando-se contra a Igreja Católica, os jesuítas, defendendo os ideais liberais da República. No entanto, em torno de 1906 
ocorreu uma reviravolta na vida de Silva, pois ao deixar a loja maçônica em que atuava, tornou-se católico praticante vinculado aos jesuítas.

Diante dessas experiências vividas, consideramos que a produção didática de Joaquim Silva trazia aspectos de sua vida profissional e política, pois o período de produção jornalística, associado à vida no magistério, foram fundamentais para a construção de um texto coeso, simples e voltado para o público escolar. A defesa dos princípios republicanos e a crença no catolicismo são elementos socioculturais significativos para a compreensão de sua escrita da História voltada ao professor e aluno do ensino secundário.

Alguns pesquisadores acreditam que a produção didática de Joaquim Silva era mais apropriada aos bancos escolares confessionais. ${ }^{7}$ Entretanto, não podemos perder de vista a força da corrente católica na Era Vargas, tanto junto às lideranças na estrutura burocrática quanto na sala de aula. Dessa forma, os livros didáticos de Joaquim Silva eram bem aceitos nas instituições públicas, pois estavam de acordo com os projetos políticos hegemônicos de seu período e correspondiam aos anseios de professores e comunidades escolares.

Como constatado, a produção didática de Joaquim Silva ocorreu a partir de 1930, em um cenário de significativas transformações no país, ao mesmo tempo em que houve a elaboração de importantes interpretações sobre a memória histórica nacional. Para a análise da interpretação difundida acerca da formação étnica do povo, utilizamos o livro intitulado História do Brasil para o Terceiro Ano Ginasial, $16^{\mathrm{a}}$ edição, publicado pela CEN em $1945 .{ }^{8}$ O livro didático que seguia a orientação curricular aprovada pelo Ministério da Educação e Saúde, deveria abordar o tema da formação do povo brasileiro na terceira unidade didática do terceiro ano ginasial, logo após a apresentação da colonização portuguesa.

Para discutir o processo de formação do povo brasileiro, Joaquim Silva adotou a mesma organização proposta pelo currículo oficial. Desse modo, essa unidade didática foi organizada com os seguintes itens: a) O elemento branco, b) O indígena brasileiro, c) O negro, d) A etnia brasileira. Tais temas foram abordados entre as páginas 86 e 107, totalizando 22 páginas, dispostas em 2 páginas para o elemento branco, 13 páginas para o indígena brasileiro (único tema que possui ilustrações), 3 páginas para o negro e 4 páginas para a etnia brasileira.

Ao analisarmos a interpretação apresentada pelo autor, elaboramos duas 
questões: quais são as qualidades atribuídas ao branco, ao indígena e ao negro em relação à formação do povo brasileiro? Quais sujeitos são considerados fundamentais para a formação do povo brasileiro na narrativa da obra didática?

No tema relativo à formação étnica do povo brasileiro, tanto pela disposição da organização curricular, quanto pela sistematização e a argumentação do texto didático de Joaquim Silva, a matriz portuguesa é compreendida como o principal elemento constituinte desse povo, tendo como elementos diversificadores o indígena e o africano.

$\mathrm{Na}$ formação do brasileiro entraram três elementos diversos: o branco, o indígena e o negro. $O$ sangue português, o elemento branco, constituiu, segundo escreve Martius, o grande rio cujos afluentes foram o índio e o africano.

Os portugueses são um dos povos europeus de mais complexa formação: descendem dos celtiberos, que remotamente habitavam a península e aos quais se mesclaram elementos fenícios, gregos, cartagineses e romanos (mediterrâneos), godos e suevos (germânicos) e árabes ou mouros (semitas). (SILVA, 1945, p. 86)

No primeiro parágrafo, Joaquim Silva trabalha duas informações básicas, por meio da metáfora de Martius: "o elemento branco constituiu o grande rio cujos afluentes foram o índio e o africano”, ressaltando que o principal elemento formador do povo brasileiro foi o português, além de registrar que o povo brasileiro é um grupo miscigenado. No entanto, para uma narrativa histórica não é aconselhável recorrer a metáforas, suas principais afirmações devem ser pautadas nas obras de referência e de prestígio entre os historiadores. Então, justificando a sua interpretação, assume um elemento discursivo para reforçá-la citando o ganhador do concurso promovido pelo IHGB, com a expressão "segundo escreve Martius". Dessa maneira, a sua singela metáfora adquiriu ares de cientificidade e de uma interpretação legitimada pelo principal órgão responsável pela elaboração e preservação da História nacional no período.

Por outro lado, o autor procurou amenizar essa assertiva, colocando entre o sujeito da frase, "o sangue português", e o verbo “constituiu”, uma explicação bastante evidente que o português é o elemento branco. Essa situação apenas se justifica por dois aspectos: dispersar o sentido de sua afirmação e ratificar que seu texto está de acordo com o programa oficial. Entre o verbo e o predicado, "o grande rio cujos afluentes são o índio e o africano", há outra explica- 
ção, a referência a Martius, com o objetivo de mostrar que a sua opinião reflete a visão de uma parte da sociedade. A palavra "afluente" contribui para essa informação básica, pois, inicialmente, o prefixo "a" indica negação. Logo, a palavra "afluente" indicaria o sentido de não fluente, ou seja, os traços culturais do indígena e do africano foram lentamente em direção da maneira de ser do português. Entretanto, o termo "afluente" faz parte do vocabulário comumente utilizado para tratar dos assuntos hidrográficos. Como ele utilizou a expressão "grande rio", é esse sentido que Joaquim Silva deseja imprimir no seu discurso, que o português foi o principal grupo formador do brasileiro, a ação e a cultura portuguesa foram fundamentais para a formação do brasileiro. Então, o brasileiro seria uma variação do português, pois os afluentes de um rio não modificam o principal rio, mas apenas o torna mais caudaloso.

Logo após a sua afirmação sobre a importância do português para a formação do povo brasileiro, começa a explicação sobre a natureza do português, afirmando que "os portugueses são um dos povos europeus de mais complexa formação". Dessa forma, assume que o português foi constituído a partir de vários elementos étnicos e culturais, dentre os quais destaca: fenícios, gregos, romanos, germânicos, árabes. Para esses povos foi constituída uma memória social, com as seguintes características: comerciantes, navegadores, filósofos, sábios, militarmente dominantes, com tecnologia desenvolvida. A complexa formação do português, associada às qualidades de seus antepassados, fundamenta a compreensão de Joaquim Silva de que os portugueses possuíam as características necessárias para fundar e construir uma nova nação. Portanto, a herança portuguesa é valorizada positivamente pelo autor, argumentando que a complexa formação desse povo foi o responsável pelos atributos de sua inteligência e sensibilidade.

Os colonos. - Ao tempo do descobrimento, bem pouco numerosa era a população de Portugal, e os que para as terras do Brasil então vieram pertenciam à nobreza lusa e outras, e a classe de plebeus, que 'foram elementos preponderantes da sociedade colonial. Desses elementos todos, fidalgos e plebeus, 'uns poucos vinham por senhores, outros, e na sua maioria, por governados, senão detentos; - melhor parte era a que pesquisava a fortuna e as aventuras, ou fugia à sanha de perseguição religiosa'. 
Eram muitos, também, os degredados; deve-se, entretanto, notar não serem todos estes, necessariamente, criminosos como ladrões ou assassinos; naquele tempo condenava-se ao degredo e a outras penas maiores por motivos que hoje não constituem delitos puníveis, havendo assim, entre os degredados, gente realmente honesta e trabalhadora. (SILVA, 1945, p. 86-87)

Joaquim Silva, ao tratar dos colonos, utilizou como referência um livro do João Ribeiro, intitulado História do Brasil, e dois livros de Oliveira Vianna, Evolução do Povo Brasileiro e Populações Meridionais do Brasil. De João Ribeiro utilizou o argumento de que os portugueses que colonizaram o Brasil eram compostos por nobres, plebeus e degredados. Da argumentação de Oliveira Vianna apresentou que os colonizadores eram nobres, plebeus, detentos, que desejam conquistar fortuna, aventuras ou fugiam da perseguição religiosa. Ainda, compartilhou do pensamento de Oliveira Vianna de que estiveram presentes no Brasil colonos de outras regiões da Europa, no entanto, de maneira insignificante. Com relação aos degredados, assinalou que representaram um número bastante reduzido, sem importância na formação do povo brasileiro, afirmando que as insinuações contrárias eram baseadas em preconceito. ${ }^{9}$

Mais uma vez, Joaquim Silva utilizou do recurso discursivo de citação para defender a sua opinião, que os colonos possuíam capacidade suficiente para construir uma grande nação. Assim, o autor optou por valorizar a base portuguesa na formação do povo brasileiro.

Em relação à matriz indígena, Joaquim Silva compartilhou da opinião na qual os povos originários do Brasil viviam de maneira semelhante aos homens da Pré-História. "Ao tempo do descobrimento nossos índios achavam-se ainda na idade neolítica, ignorando o uso dos metais. Obtinham o fogo pelo prolongado atrito de dois paus. Alimentavam-se com frutas e produtos de caça e pesca" (SILVA, 1945, p. 94).

A apresentação sobre o indígena brasileiro foi organizada por meio de um texto linear com as características principais dos grupos estudados, acompanhada de notas de rodapé em que há citações e trechos dos livros que utilizou como referência para o seu argumento. Desse modo, o texto didático oferece uma leitura direta para o aluno e a fundamentação de sua narrativa para o professor. Nesse tema, utilizou como referência: R. Furano, Prehistoire Générale, Serrano, História do Brasil, Pittard, Les races et l'Histoire, Pagdberg-Dre- 
nhpol, Calmon, História da Civilização Brasileira, Abreu, Capitulos da História Colonial, Calmon, História do Brasil, Plínio Airosa, Afonso A. de Freitas, Os Guaianos de Piratininga, Roquete Pinto, Padre Colbacchini, Abreu, Descobrimento do Brasil, Cardim, Tratado da Terra do Brasil, Padre Serafim Leite, História da Companhia de Jesus no Brasil.

No decorrer do texto, Joaquim Silva apresentou as características sociais, econômicas, políticas e culturais dos indígenas, deixando evidente que o modo de vida do brasileiro era distinto das suas maneiras de ser e viver. $\mathrm{O}$ autor descreveu as formas de alimentação, de vestimenta, da relação com a guerra, do casamento, da religião, os grupos linguísticos, utilizando também ilustrações de Rugendas para exemplificar seus tipos físicos. Citando Serrano, Silva acredita que a visão romântica sobre o indígena é uma ficção elaborada pela literatura. No final da unidade, relaciona sua importância na formação do povo brasileiro.

Nos primeiros tempos da colônia foi notável a influência do indígena sobre os costumes e mesmo sobre a linguagem dos brancos, que com ele conviviam.

A própria língua dos colonos sofreu o influxo dos aborígenes; não só numerosos nomes de lugares ou acidentes geográficos, pessoas, plantas, animais são de origem tupi mas, ainda, até o começo do século XVIII, era corrente o uso da língua dos índios ao lado da portuguesa (SILVA, 1945, p. 98).

Para descrever a matriz indígena, Joaquim Silva optou pela discussão historiográfica e etnográfica, as quais frisavam a diferença entre a maneira de ser desse grupo e a do colono. A partir do texto didático, fica a ideia de que os indígenas tiveram participação diminuta na formação do povo brasileiro, restringindo-se à nomeação de lugares, pessoas, fauna e flora. Portanto, embora a cultura indígena tenha contribuído em alguns aspectos, ela não é valorizada como o elemento fundamental da sociedade brasileira.

No decorrer do livro analisado, nota-se o objetivo de mostrar que os indígenas no Brasil não formavam um grupo homogêneo, pois podiam ser divididos em dois grandes segmentos, os tupis-guaranis e os tapuias, que falavam idiomas diferentes. Então, se no Brasil há um idioma predominante, não era possível evidenciar uma herança indígena relevante.

Para tratar da matriz africana, o autor utilizou apenas o título O Negro, 
não descrevendo em detalhes as características dos grupos que vieram para o Brasil. De forma sintética, relacionou seu modo de vida próprio com o do período da Idade dos Metais. O primeiro parágrafo dessa parte apresenta a ideia de que os indígenas não resolviam de maneira satisfatória a quantidade de trabalhadores necessários à produção na colônia portuguesa. Por isso, justifica-se a necessidade de a importação da mão de obra escravizada proveniente de algumas regiões da África.

Desde os primeiros anos da colônia recorreram os portugueses ao escravo negro para os árduos trabalhos da lavoura e outros aos quais não se prestavam bem os indígenas, que a proteção dos jesuítas e as leis do reino não permitiam escravizar. Da África, terra da escravidão, era possível trazer, aos milhares, pretos que já eram escravizados por seus régulos e que, vindos para o Brasil, trocavam um cativeiro por outro, aliás, menos desumano que o sofrido na terra natal. (SILVA, 1945, p. 101)

Joaquim Silva destacou a função desempenhada pelo negro entre os séculos XVI e XVIII, mão de obra essencial para a obra colonizadora portuguesa. O elemento é apresentado como fundamental nesse parágrafo. No entanto, a ação dos portugueses no processo de escravização é minimizada pelo autor, pois independente dos colonizadores, a África era a "terra da escravidão". Como já havia escravizados entre os próprios africanos, o português apenas comercializava os escravizados. Por fim, justifica a escravidão na medida em que afirma que o cativeiro no Brasil era mais humano do que na África.

No segundo trecho, Joaquim Silva desqualifica a religiosidade dos africanos, pois segundo ele apenas uma parte dos africanos acreditava em Deus, ou melhor, no Deus que os portugueses acreditavam. Portanto, o autor afirmava que havia uma grande quantidade de infiéis, pagãos, que poderiam ser explorados.

Havia muitos, nas tribus mais adiantadas, que acreditavam no Creador; a maioria, porém, era grosseiramente feiticista. Dentre os sudaneses contavam-se os mais desenvolvidos e de mais perfeito físico; no grupo dos berberes encontravam-se tradições árabes ou muçulmanas. (SILVA, 1945, p. 101-102) 
A partir desse ponto, Joaquim Silva trata das contribuições dos africanos na formação do povo brasileiro, concluindo que

foi grande a influência exercida pelo escravo negro no Brasil; uma antiga crônica referia mesmo que "os escravos são as mãos e os pés do senhor de engenho, porque sem eles, no Brasil, não é possível fazer, conservar ou aumentar fazenda, nem ter engenho corrente". Não só na vida econômica, porém, se verificava tamanho influxo; também na constituição do tipo brasileiro, na formação moral, nos usos e costumes, e até na linguagem.

Dos costumes e usos africanos ficaram certas danças (congadas, cateretês) e, na arte culinária, particularmente nalguns estados, a confecção de grande número de iguarias como o vatapá, o cururu, o bobó, o acarajé, o mungunzá, o cuscuz.

$\mathrm{Na}$ poesia popular encontram-se vestígios da influência do negro, assim como nos contos e tradições. Na linguagem nacional assinala-se o influxo africano pela introdução de numerosas palavras.

As crendices, as superstições dos pretos, com sua afetividade, refletiram-se na formação de nossa gente que deles herdou "uma certa negligência creoula, uma resignação heróica para suportar a miséria, uma concepção um pouco fatalista e quiça leviana da vida, sem grandes preocupações do futuro, o hábito do trabalho sem amor, mas também sem revolta, e, enfim, a melancolia impressa mais na música e na poesia do que no estado de alma habitual do povo". (SILVA, 1945, p. 102-103)

O termo "influxo" é utilizado no sentido de estabelecer a relação entre o negro e a formação do povo brasileiro. No entanto, o prefixo "in" indicaria uma não-influência, ou uma influência de maneira ruim. É bastante evidente que Joaquim Silva procurou minimizar as contribuições do negro na formação do povo brasileiro, pois trata suas manifestações religiosas como crendice e superstição, afirma que este é um ser sem preocupações com o futuro, visto que trabalha sem empenho, mesmo o colocando na época colonial como a mão de obra que movimentava as fazendas e os engenhos.

Joaquim Silva argumentou em sua obra didática que o brasileiro não poderia ser considerado um sujeito integrante de uma raça pura. Segundo o autor, desde o início da época colonial as raças formadoras caldearam-se, dando origem ao povo brasileiro. Em outro sentido, o brasileiro só pode existir a partir do momento em que o português chegou nesse território. Enfaticamen- 
te, o ser brasileiro é fruto da miscigenação, assim o povo brasileiro não seria homogêneo.

A absorção ou assimilação de elementos indígenas e pretos na massa de nossa população continua-se, a par de contingentes portugueses, italianos, alemães, sírios, eslavos e outros que afluem do Velho Mundo. As estatísticas mostram que, pela situação estacionária da raça negra e redução do fator indígena cresce, cada vez mais, nos grupos mestiços, a porcentagem de sangue branco.

Não há em nossa terra preconceitos ou questões raciais; e por isso, o grande estadista americano Teodoro Roosevelt, com razão, notou que o futuro nos reserva uma grande benção; "ter evitado e solvido um problema altamente perigoso, quiçá mortal - um conflito racial de vida e morte”. (SILVA, 1945, p. 105)

A palavra "assimilação" contribui para a reflexão sobre a população brasileira, pois ela se articula com "nossa população". Assim, o núcleo central da população brasileira é o elemento português, grupo mestiço branco, que se apropriou dos traços culturais dos indígenas e dos negros, a fim de assegurar a sua melhor adaptação no território brasileiro. Ainda, em relação à população, o autor sugere que há um grande grupo mestiço, mas que o elemento branco é grupo dominante e sintetizador da cultura, é ele que deve incorporar, à sua maneira de ser, os traços culturais do indígena e do negro. Implicitamente está o ideal de branqueamento da população brasileira, fortalecido pelo processo de imigração de pessoas provenientes da Europa. Com a expressão "cresce, cada vez mais, nos grupos mestiços, a porcentagem de sangue branco", Joaquim Silva afirma que o povo mestiço brasileiro está em um processo de branqueamento.

Dessa maneira, o autor valoriza o povo branco europeu, considerando este o grupo mais desenvolvido. No entanto, procura negar a existência de preconceitos sociais e raciais no país, ou seja, o Brasil seria formado por grupos bastante heterogêneos, mas que conseguem viver em harmonia, superando suas diferenças étnicas e construindo uma sociedade pacífica, superando inclusive as condições adversas observadas nos Estados Unidos da América. 


\section{CONSIDERAÇÕES FINAIS}

Trabalhando no contexto da Reforma Capanema, Jonathas Serrano elaborou o currículo de História para o ensino secundário correspondendo aos ideais do Estado Novo. Em sua proposta, considerada inovadora no período, permanecia vinculada a uma interpretação histórica tradicional, pautada na narração da construção do Estado, na importância da nação, no estudo dos heróis como exemplos de conduta moral, no caráter humanístico para o sistema de ensino. Em certo sentido, o currículo de História acabou expressando posições ideológicas conciliatórias entre católicos, militares e, com menos intensidade, escolanovistas.

O experiente professor Joaquim Silva, descendente de portugueses, fiel católico alinhado aos jesuítas, autor dos livros didáticos de História mais vendidos pela CEN entre as décadas de 1930 e 1960, construiu uma narrativa voltada para o apagamento das diferenças entre os elementos que compunham o povo brasileiro, valorizando uma vida social sem conflitos e justificando as desigualdades sociais, estando em conformidade com o conceito de solidariedade proposto pelo Estado Novo e presente nas interpretações de Oliveira Vianna.

Os textos do renomado autor de livros didáticos não deixavam de ser ambivalentes, sobretudo com relação ao indígena e ao negro. Se o elemento branco era considerado o grupo basilar para a formação do brasileiro, a principal matriz da raça e da cultura brasileira, o indígena fazia parte do grupo que foi cristianizado para tornar-se um elemento formador do povo, o mais assimilável, ou até o mais receptivo à ação do colonizador e do jesuíta. Entretanto, nem todo indígena era suscetível ao modelo imposto pelo colonizador. Os mais selvagens foram combatidos justamente, pois atravancavam o progresso e não contribuíam com o ideal de unidade cultural. Por sua vez, o elemento negro serviu como mão de obra principal, trouxe costumes alimentares e culturais marcantes. Porém, também promoveu desvirtuamentos na formação da alma do brasileiro, ao trabalhar sem vontade e amor, ao não lutar pela transformação de sua condição, ao aceitar passivamente o que os outros lhes impõem.

Como narrativas ambivalentes nem sempre são bem quistas, por mais que as práticas de leitura pudessem gerar múltiplas interpretações, o povo brasileiro desejado pelas elites políticas e intelectuais parecia representado nas pá- 
ginas do livro didático analisado: um elemento mestiço em processo de branqueamento, trabalhador, pacífico, cristão, temente a Deus e submisso ao Estado vigente.

\section{REFERÊNCIAS}

ABUD, Kátia. Currículos de História e política públicas: os programas de História do Brasil na escola secundária. In: BITTENCOURT, Circe Maria Fernandes (Org.). O saber histórico na sala de aula. 12. ed. São Paulo: Contexto, 2013. p. 28-41.

BITTENCOURT, Circe Maria Fernandes. Pátria, civilização e trabalho: o ensino de História nas escolas paulistas. São Paulo: Edições Loyola, 1990.

BITTENCOURT, Circe Maria Fernandes. Ensino de História: fundamentos e métodos. São Paulo: Cortez, 2004.

BITTENCOURT, Circe Maria Fernandes. Livros didáticos entre textos e imagens. In: BITTENCOURT, Circe Maria Fernandes (Org.). O saber histórico na sala de aula. 12. ed. São Paulo: Contexto, 2013.

BRASIL. Decreto no 19.402, de 14 de novembro de 1930. Diário Oficial da União. Poder Executivo, Rio de Janeiro, DF, 18 de novembro de 1930, Seção 1, p. 20.883.

BRASIL. Lei no 378, de 13 de janeiro de 1937. Diário Oficial da União. Poder Executivo, Rio de Janeiro, DF, 15 de janeiro de 1937, Seção 1, p. 1210.

BRASIL. Decreto-Lei no 4.244, de 9 de abril de 1942. Diário Oficial da União. Poder Executivo, Rio de Janeiro, DF, 10 de abril de 1942, Seção 1, p. 5798.

BRASIL. Portaria Ministerial no 101, de 27 de abril de 1942. Diário Oficial da União. Poder Executivo, Rio de Janeiro, DF, 28 de abril de 1942, Seção 1.

COELHO, Mauro Cesar. A história, o índio e o livro didático: apontamentos para uma reflexão sobre o saber histórico escolar. In: ROCHA, Helenice Aparecida Bastos; REZNIK, Luís; MAGALHÃES, Marcelo de Souza (Org.). A história na escola: autores, livros e leituras. Rio de Janeiro: Editora FGV, 2009.

DALLABRIDA, Norberto. A reforma Francisco Campos e a modernização nacionalizada do ensino secundário. Educação, Porto Alegre, v. 32, n. 2, p. 185-191, maio/ ago. 2009.

ESCOLANO BENITO, Agustín. Currículum editado y sociedad del conocimiento: texto, multimedialidad y cultura de la escuela. Valencia: Tirant lo Blanch, 2006.

FAUSTO, Boris. Getúlio Vargas: o poder e o sorriso. São Paulo: Companhia das Letras, 2006.

FERNANDES, Eunícia Barros Barcelos. Imagens de índios e livro didáticos: uma reflexão sobre representações, sujeitos e cidadania. In: ROCHA, Helenice Aparecida 
Bastos; REZNIK, Luís; MAGALHÃES, Marcelo de Souza (Org.). A história na escola: autores, livros e leituras. Rio de Janeiro: Editora FGV, 2009.

FERREIRA, Rita de Cassia Cunha. A Comissão Nacional do Livro Didático durante o Estado Novo (1937-1945). Dissertação (Mestrado em História). Faculdade de Ciências e Letras de Assis, Universidade Estadual Paulista, Assis, 2008. 139 f. Disponível em: https://repositorio.unesp.br/handle/11449/93413. Acesso em: 29 nov. 2019.

FONSECA, Thais Nívia de Lima e. História \& ensino de História. Belo Horizonte: Autêntica, 2006.

FRANZINI, Fábio; LOURENÇO, Elaine. Quando historiadores foram à escola: a história do Brasil de Octavio Tarquínio de Sousa e Sérgio Buarque de Holanda (1944) e os ecos da nova historiografia brasileira. Revista Expedições: Teoria da História \& Historiografia, Morrinhos (GO), v. 8, n. 1, p. 1-18, jan./abr. 2017.

FREITAS, Itamar. A historiografia escolar na Comissão Nacional do Livro Didático: pareceres de Jonathas Serrano (1938/1941). História \& Ensino, Londrina, v. 12, p. 141-156, ago. 2006.

GASPARELLO, Arlette Medeiros. Construtores de Identidade: a pedagogia da nação nos livros didáticos da escola secundária brasileira. São Paulo: Iglu Editora, 2004.

GOMES, Ângela de Castro. Cultura política e cultura histórica no Estado Novo. In: ABREU, Martha; SOIHET, Rachel; GONTIJO, Rebeca (Org.). Cultura politica e leituras do passado: historiografia e ensino de História. Rio de Janeiro: Civilização Brasileira, 2007.

GOODSON, Ivor Frederick. Currículo: teoria e história. Petrópolis: Vozes, 1995.

LENHARO, Alcir. Sacralização da política. Campinas: Papirus, 1986.

MARTINS, Maria do Carmo. A história prescrita e disciplinada nos currículos escolares: quem legitima esses saberes? Coleção Estudos CDAPH. Série História \& Ciências Sociais. Bragança Paulista: EDUSF, 2002.

MORAES, Didier Dias de. O design de Eugênio Hirsch para livros didáticos da Companhia Editora Nacional. Estudos em Design, Rio de Janeiro, v. 26, n. 1, p. 132-153, jan./abr. 2018.

MORENO, Jean Carlos. Quem somos nós? Apropriações e representações sobre a(s) identidade(s) brasileira(s) em livros didáticos de História (1971-2011). Tese (Doutorado em História). Faculdade de Ciências e Letras de Assis, Universidade Estadual, Assis, 2013. 381 f. Disponível em: https://repositorio.unesp.br/handle/11449/103146. Acesso em: 22 out. 2019.

PEREIRA, Baptista. A formação espiritual do Brasil. São Paulo: Saraiva \& Cia, 1930.

PEREIRA, Júnia Sales. Do colorido à cor: o complexo identitário na prática educativa. 
In: GONÇALVES, Márcia de Almeida et al. (Org.). Qual o valor da história hoje? Rio de Janeiro: Editora FGV, 2012.

PINTO JUNIOR, Arnaldo. Professor Joaquim Silva, um autor da história ensinada no Brasil: livros didáticos e educação moderna dos sentidos (1940-1951). Tese (Doutorado em Educação). Faculdade de Educação, Universidade Estadual de Campinas, Campinas, 2010. 273 f. Disponível em: http://repositorio.unicamp.br/handle/ REPOSIP/251503. Acesso em: 15 nov. 2019.

REZNIK, Luís. Tecendo o amanhã. A História do Brasil no ensino secundário: programas e livros didáticos (1931 a 1945). Dissertação (Mestrado em História). Instituto de Ciências Humanas e Filosofia, Universidade Federal Fluminense, Niterói, 1992. $288 \mathrm{f}$.

REZNIK, Luís. O lugar da História do Brasil. In: MATTOS, Ilmar Rohloff de (Org.). Histórias do ensino da história no Brasil. Rio de Janeiro: Acess, 1998.

RIBEIRO JÚNIOR, Halferd Carlos. O sistema de ensino ginasial e livros didáticos: interpretações da Independência brasileira de Joaquim Silva entre 1946 e 1961. Dissertação (Mestrado em História). Faculdade de Ciências Humanas e Sociais, Universidade Estadual Paulista, Franca, 2008. 136 f. Disponível em: https://repositorio. unesp.br/handle/11449/93271. Acesso em: 11 set. 2019.

RIBEIRO JÚNIOR, Halferd Carlos. Ensino de História e identidade: currículo e livro didático de História de Joaquim Silva. Tese (Doutorado em Educação). Faculdade de Educação, Universidade Estadual de Campinas, Campinas, 2015. 266 f. Disponível em: http://repositorio.unicamp.br/jspui/handle/REPOSIP/254123. Acesso em: 08 nov. 2019.

SANTOS, Beatriz Boclin Marques dos. O currículo da disciplina História no Colégio Pedro II - a década de 1970 - entre a tradição acadêmica e a tradição pedagógica: a História e os Estudos Sociais. Tese (Doutorado em Educação). Centro de Filosofia e Ciências Humanas, Universidade Federal do Rio de Janeiro, Rio de Janeiro, 2009. 294 f. Disponível em: http://www.dominiopublico.gov.br/pesquisa/DetalheObraForm.do?select_action=\&co_obra=163178. Acesso em: 08 nov. 2019.

SCHWARTZMAN, Simon; BOMENY, Helena Maria Bousquet; COSTA, Vanda Maria Ribeiro. Tempos de Capanema. $2^{\text {a }}$ ed. São Paulo: Fundação Getúlio Vargas; Paz e Terra, 2000.

SILVA, Joaquim. História do Brasil para o Terceiro Ano Ginasial. 16ª ed. São Paulo: Companhia Editora Nacional, 1945.

SKIDMORE, Thomas Elliot. De Getúlio Vargas a Castelo Branco (1930-1964). Coleção Imagem do Brasil, v. 9. Rio de Janeiro: Saga, 1969.

VESENTINI, Carlos Alberto. A teia do fato: uma proposta de estudo sobre a memória histórica. São Paulo: Editora Hucitec; História Social - USP, 1997.

VIANA, Larissa. Mestiçagem e cultura histórica: debates. In: Abreu, Martha; SOIHET, 
Rachel; GONTIJO, Rebeca (Org.). Cultura política e leituras do passado: historiografia e ensino de História. Rio de Janeiro: Civilização Brasileira, 2007.

\section{NOTAS}

${ }^{1}$ Criado pelo Decreto no 19.402, de 14 de novembro de 1930, o Ministério dos Negócios da Educação e Saúde Pública teve sua denominação alterada no dia 13 de janeiro de 1937, pela Lei n ${ }^{\circ} 378$, quando passou a ser conhecido como Ministério da Educação e Saúde.

${ }^{2}$ Os professores eram: Coronel Pedro Mariani Serra, Sousa da Silveira, Ernesto de Faria, Maria Junqueira Schmidt, Osvaldo Serpa, Euclides Roxo, Costa Ribeiro, João Pecegueiro, Melo Leitão, Jônatas Serrano, Delgado de Carvalho, Neréu Sampaio, Rocha Lima, Heitor Villa-Lobos e Germaine Marsaud. Cf. Portaria Ministerial n 101, de 27 de abril de 1942 (BRASIL, 1942).

${ }^{3}$ Em relação ao desenvolvimento cognitivo do aluno para o estudo da história, pode-se conferir o livro intitulado Ensino de História: fundamentos e métodos, de Circe Maria Fernandes Bittencourt (2004), em especial o momento relativo à discussão apresentada sobre Piaget e Vygotsky.

${ }^{4}$ Para uma análise mais detalhada, conferir a tese de Halferd Carlos Ribeiro Júnior (2015), intitulada Ensino de História e identidade: currículo e livro didático de História de Joaquim Silva.

${ }^{5}$ Para maiores informações sobre a formação sociocultural, experiências docentes e produções didáticas de Joaquim Silva, consultar a tese de Pinto Junior (2010), que apresenta a trajetória de vida do autor desde as relações familiares na cidade natal até sua condição de principal autor de História na CEN..

${ }^{6}$ Além das informações coletadas nas respectivas instituições de ensino, sua experiência profissional é registrada nas páginas iniciais dos livros didáticos História da Civilização, publicados pela Companhia Editora Nacional (CEN) entre 1938 e 1942 (PINTO JUNIOR, 2010).

${ }^{7}$ As obras de Joaquim Silva foram analisadas de forma mais ampla nos trabalhos de Pinto Junior (2010) e Ribeiro Júnior $(2008,2015)$. Outros pesquisadores também abordaram suas produções didáticas, trazendo contribuições sobre posicionamento no mercado editorial, concepções pedagógicas e históricas (FRANZINI; LOURENÇO, 2017; MORAES, 2018; MORENO, 2013). Com relação ao ensino secundário e a disciplina escolar História, conferir os trabalhos de Abud (2013), Bittencourt (1990), Fonseca (2006), Martins (2002) e Reznik (1998).

${ }^{8}$ O livro didático de Joaquim Silva, intitulado História do Brasil para o Terceiro Ano Ginasial, publicado em 1950, apresentava na contracapa a inscrição Livro de Uso Autorizado pelo Ministério da Educação e Saúde sobre o nº 611. A mesma editoração e paginação da 
referida obra é observada desde o ano de 1943, quando foi impressa a terceira edição consultada nesta pesquisa.

${ }^{9}$ Os livros didáticos do autor, publicados entre os anos 1930 e 1940, invariavelmente traziam informações das obras de referência em notas de rodapé. Considerando que os intensos debates sobre a formação do povo brasileiro, a identidade nacional e a mestiçagem não estão no escopo desta pesquisa, concentramos nossa análise nas perspectivas históricas da obra focalizada. Para o estudo dos referidos debates na relação com o ensino de História, conferir os trabalhos de Bittencourt (2013), Coelho (2009), Fernandes (2009), Pereira (2012), Viana (2007), dentre outras pesquisas que abordam a relevante temática.

Artigo recebido em 11 de dezembro de 2019. Aprovado em 19 de janeiro de 2020. 